\title{
Premix for Medicated Feeding Stuff Dosage Form
}

\author{
National Cancer Institute
}

\section{Source}

National Cancer Institute. Premix for Medicated Feeding Stuff Dosage Form. NCI

Thesaurus. Code C149864.

Liquid, semi-solid or solid preparation intended to facilitate oral administration of active substances to animals. Premixes for medicated feeding stuff are used exclusively in the preparation of medicated feeding stuffs. Used as powders or granules, they are freeflowing and homogeneous. Used in liquid form, they are homogeneous suspensions or solutions which may be obtained from thixotropic gels or structured liquids. The particle size and other properties are such as to ensure uniform distribution of the active substance(s) in the final feeding stuff. 